\title{
Discovery of anatomic variant of saphenous nerve from human cadaver dissection
}

\author{
AHMAD, U. ${ }^{1,2}$, SAN, A. A. ${ }^{1}$, SEE, C. P. ${ }^{1,3}$, TAIB, C. N. M. ${ }^{1}$, \\ MOKLAS, M. A. B. M. ${ }^{1}$ and OTHMAN, $\mathrm{F}^{1}{ }^{*}$
${ }^{1}$ Department of Human Anatomy, Faculty of Medicine and Health Sciences, Universiti Putra Malaysia, 43400 UPM Serdang, Selangor, Malaysia
${ }^{2}$ Department of Anatomy, Faculty of Medical Sciences, Bauchi State University, Main Campus, PMB 65 Gadau, Itas/Gadau, Nigeria
${ }^{3}$ Genetic and Regenerative Medicine Research Center, Faculty of Medicine and Health Sciences, Universiti Putra Malaysia, 43400 UPM Serdang, Selangor, Malaysia
*E-mail: fauziah@upm.edu.my

\begin{abstract}
Introduction: Saphenous nerve is the longest and largest pure sensory nerve, supplying the medial side of the thigh, leg and foot. Materials and Methods: In the present case study, during routine cadaveric dissection of the antero-medial part of the thigh, an interesting anomalous pattern of saphenous nerve was seen in the right lower limb of a 62 years old embalmed male cadaver from the Department of Human Anatomy, Universiti Putra Malaysia (UPM). Results: This saphenous nerve can be recognised as an unusual anatomical variant in which it gives a motor branch to the sartorius muscle during traversing the adductor canal and it was accompanied by blood vessels at the same time. The nerve continues its usual course and pierces the fascia lata, between the tendon of sartorius and gracilis and becomes subcutaneous. Conclusion: Knowledge of the variant anatomy of the saphenous nerve is important to surgeon in avoiding nerve injuries during adductor canal nerve block, nerve entrapment surgery, reconstructive surgery, pain management services and knee surgery successfully.
\end{abstract}

Keywords: anatomical variant, motor branch of saphenous nerve, vessels, sartorius.

\section{Introduction}

The saphenous nerve is the largest and pure sensory cutaneous branch of posterior division of the femoral nerve (HUNTER, LOUIS, RICCIARDI et al., 1979), originating from the nerve roots, L2, L3, and L4 (MOORE, 1992; NETTER, 1997; WALDMAN, 2013). It supplies sensation to the anteromedial aspect of the lower limb, primarily through two major divisions: the sartorial and infrapatellar nerves (HUNTER, LOUIS, RICCIARDI et al., 1979). It descends anteroinferiorly passing through the femoral triangle, lateral to the femoral sheath, accompanying the femoral artery in the adductor canal (VERMA, MISHRA and MAHAJAN, 2013), and then courses between the sartorius and gracilis muscles across the anterior thigh (WALDMAN, 2013). On its course to the leg inferior medially, it gives an infrapatellar branch (MOORE, 1992), which pierces the fascia lata of sartorius and provides sensory innervation to the skin covering the knee (patella). This branch then curves laterally, inferior to the patella (BADEMKIRAN, OBAY, AYDOGDU et al., 2007), and joins with branches from the medial cutaneous femoral nerve, forming the infrapatellar plexus (MOORE, 1992; TOTHONGLOR, AGTHONG, HUANMANOP et al., 2013).

Then, the other branch of the saphenous nerve exits between the sartorius and gracilis tendons and continues inferiorly to innervate the anteromedial part of the lower leg and dorsum of the foot (ASZMANN, EBMER and DELLON, 1998; EBRAHEIM and MEKHAIL, 1997). Many cases of saphenous nerve variation have been reported in literature (HEMLER, WARD, KARSTETTER et al., 1991; PRATT, 2005), but there is no literatures reporting on saphenous nerve giving a motor branch to the sartorius while accompanying by blood vessel as well as supplying vastus medialis muscle in the thigh.

\section{Case Study}

During routine practical and dissection class of the lower limb at the Department of Human Anatomy, Faculty of Medicine and Health Sciences, Universiti Putra Malaysia (UPM), a 62-years old donated embalmed male cadaver was found with an anomalous saphenous nerve in his right thigh of the lower limb (Figure 1). When exposing the adductor canal, in addition to the usual course of the saphenous nerve in the adductor canal, the saphenous nerve gave off a muscular branch to the sartorius muscle and was accompanied by the blood vessels from the femoral vessels (refer to the picture below). Together with these vessels, the nerve entered into the sartorius muscle (Figure 1). The saphenous nerve then continued to pierce the deep fascia of the thigh between the sartorius and gracilis muscles to become subcutaneous and descended along the medial side of the leg where it accompanied with the great saphenous vein. The dissection was continued to other muscular and cutaneous branches of the femoral nerve where we found that nerves to vastus medialis were also originated from the upper part of the saphenous nerve in this cadaver. 


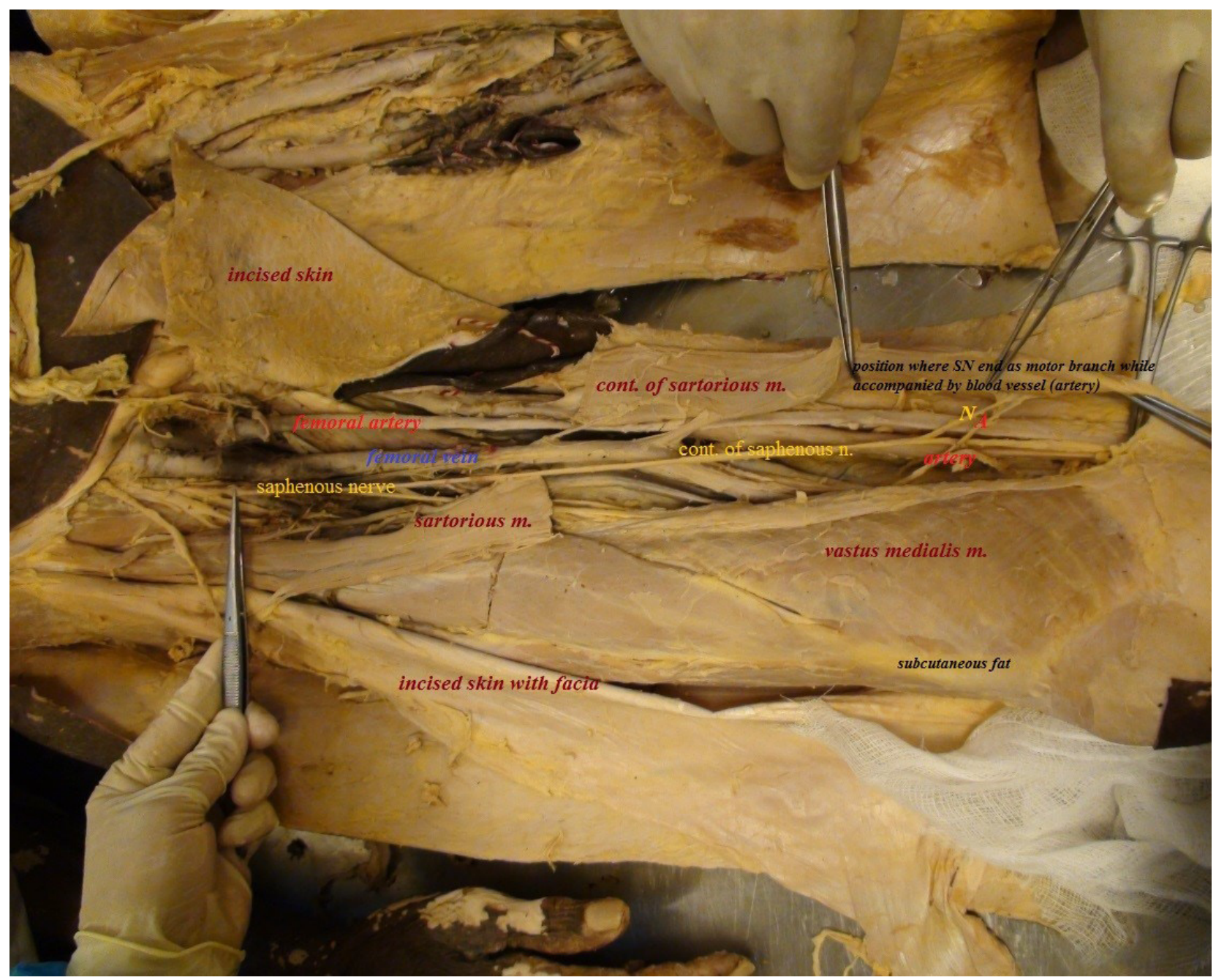

Figure 1. Photographic picture of the antero-medial aspect of the thigh showing subcutaneous saphenous nerve together with its associated structures. N: Motor branch of the saphenous nerve; A: Accompanied blood vessel (artery). Note: The saphenous nerve gives branch to the sartorius and continues as subcutaneous (black ink from the figure). Nerve to vastus medialis arises from the upper part of the saphenous nerve.

\section{Discussion}

The saphenous nerve arises from posterior division of femoral nerve (VERMA, MISHRA and MAHAJAN, 2013) and followed the normal course in the femoral triangle (BADEMKIRAN, OBAY, AYDOGDU et al., 2007). In the proximal part of the adductor canal, the nerve traversed beneath the sartorius and is located anterior to the femoral artery. In the medial twothird of the thigh, inferiorly, the saphenous gives branch to the sartorius muscle and continued in the superficial plane, medial to the knee and the leg. This is mostly a rare case finding where saphenous nerve gives off a branch that supplied the sartorius muscle and become subcutaneous, while supplying the medial side of the knee and accompanied by blood vessels. Saphenous nerve usually follow its normal course by descending vertically, along the medial side of the knee behind the sartorius pieces the fascia lata between the tendon of the sartorius and gracilis, and become subcutaneous (GRAY and CLEMENTE, 1985).

No literature was found to have described that the saphenous nerve gives off a branch to supply sartorius muscle, ending as a motor branch and innervate vastus medialis muscle as well.
From there, it was then continued inferior medially to supply the medial side of the leg and ankle. Moore (1992) states that as the saphenous nerve run inferior medially, it gives off an infrapatellar branch that innervates the knee (patella), after piercing the sartorius muscle. In our finding of the branch to the sartorius is accompanied by the blood vessels from the femoral vessels and the given branch can be considered as motor branch to the sartorius not cutaneous nerve as usually being found in human.

Most anaesthesiologists often performed Adductor Canal Block (ACB) than Femoral Nerve Block (FNB) to preserve quadriceps muscle strength in knee surgery (JENSTRUP, JÆGER, LUND et al., 2012). Knowledge of variant saphenous nerve of the lower limb is useful for clinicians and orthopaedic surgeons during lower limb nerve block procedures (AKKAYA, ERSAN, OZKAN et al., 2008; WALDMAN, 2013), as this nerve is commonly encounter during surgery. It is therefore, essential for surgeons and anaesthesiologists before carrying out operation and/or nerve block to the lower limbs to look for the possible variation in this subcutaneous nerve (saphenous nerve), in order to avoid damaging some of the given branches 
of the nerve variants. Our finding may give the awareness in doing the saphenous nerve block in adductor canal will give not only sensory block but can also have the motor block of the muscles that bounded the adductor canal.

Acknowledgements: The authors are thankful to the Head, Department of Human Anatomy, Universiti Putra Malaysia, for showing interest to this discovery of nerve variation from the lower limbs and made it encouraging for the publication to take effect.

\section{References}

AKKAYA, T., ERSAN, O., OZKAN, D., SAHINER, Y., AKIN, M., GÜMÜŞ, H. and ATEŞ, Y. Saphenous nerve block is an effective regional technique for post-menisectomy pain. Knee Surgery, Sports Traumatology. Arthroscopy: Official Journal of the ESSKA, 2008, vol. 16, p. 855-858. http://dx.doi.org/10.1007/s00167-008-0572-4.

ASZMANN, OC., EBMER, JM. and DELLON, AL. Cutaneous innervation of the medial ankle: an anatomic study of the saphenous, sural, and tibial nerves and their clinical significance. Foot \& Ankle International / American Orthopaedic Foot and Ankle Society. Swiss Foot and Ankle Society, 1998, vol. 19, p. 753-756. http://dx.doi. org/10.1177/107110079801901108.

BADEMKIRAN, F., OBAY, B., AYDOGDU, I. and ERTEKIN, C. Sensory conduction study of the infrapatellar branch of the saphenous nerve. Muscle \& Nerve, 2007, vol. 35, p. 224-227. http://dx.doi. org/10.1002/mus.20682.

EBRAHEIM, NA. and MEKHAIL, AO. The infrapatellar branch of the saphenous nerve: an anatomic study. Journal of Orthopaedic Trauma, 1997, vol. 11, p. 195-199. http://dx.doi.org/10.1097/00005131199704000-00010.

GRAY, H. and CLEMENTE, CD. Anatomy of the human body. Washington: Lea \& Febiger, 1985.

HEMLER, DE., WARD, WK., KARSTETTER, KW., and BRYANT, PM. Saphenous nerve entrapment caused by pes anserine bursitis mimicking stress fracture of the tibia. Archives of Physical Medicine and Rehabilitation, 1991, vol. 72, p. 336-337. http://dx.doi. org/0003-9993(91)90253-F.
HUNTER, LY., LOUIS, DS., RICCIARDI, JR. and O'CONNOR, GA. The saphenous nerve: its course and importance in medial arthrotomy. The American Journal of Sports Medicine, 1979, vol. 7, n. 4 , p. 227-230.

JENSTRUP, MT., JÆGER, P., LUND, J., FOMSGAARD, JS., BACHE, S., MATHIESEN, O. and DAHL, JB. Effects of AdductorCanal-Blockade on pain and ambulation after total knee arthroplasty: A randomized study. Acta Anaesthesiologica Scandinavica, 2012, vol. 56, p. 357-364. http://dx.doi.org/10.1111/j.1399-6576.2011.02621.x.

MOORE, K. The lower limb. In KEITH L. MOORE. Clinically oriented anatomy. 3rd ed. Baltimore: Williams and Wilkins, 1992. p. $403-468$.

NETTER, F. H. Lower limb. In FRANK H. NETTER. Atlas of human anatomy. 2nd ed. Teterboro: ICON Learning Systems, 1997. p. 502-509.

PRATT, N. Anatomy of nerve entrapment sites in the upper quarter. Journal of Hand Therapy, 2005. http://dx.doi.org/10.1197/j. jht.2005.02.004.

TOTHONGLOR, A., AGTHONG, S., HUANMANOP, T. and CHENTANEZ, V. Sartorial branch of saphenous nerve: anatomical relationship with bony landmarks and great Saphenous Vein. International Journal of Morphology, 2013, vol. 31, n. 2, p. 432-437.

VERMA, R., MISHRA, S. and MAHAJAN, A. Subcutaneous course of saphenous nerve in midthigh. International Journal of Anatomy and Research, 2013, vol. 1, n. 3, p. 181-182.

WALDMAN, SD. Saphenous nerve block. Atlas of Pain Management Injection Techniques, 2013, p. 407-409. http://dx.doi.org/10.1016/ B978-1-4377-3793-6.10135-4. 